\title{
La poética del cine y la cuestión del método en el análisis fílmico*
}

*EI presente trabajo fue realizado con auxilio del CNPq, entidad del Gobierno brasileño destinada al apoyo de la investigación científica. $\mathrm{El}$ autor agradece a los investigadores del Laboratorio de Análisis de Ficción Audiovisual del Programa de Pós-Graduação em Comunicação e Cultura Contemporâneas por la relevante contribución en la elaboración de este ensayo.

WILSON GOMES

Universidade Federal da Bahia/UFB 


\section{Resumen}

Este artículo discute la necesidad y la oportunidad de plantear cuestiones de método, en lo que se refiere a la discusión sobre los procedimientos de análisis fílmico. Examina las razones por las cuales la instancia de análisis de filmes, considerada aquí como un campo social, ve con desconfianza las demandas de un posicionamiento metódico. Luego discute por qué - al contrario - las cuestiones de método son inevitables y fecundas y deberían ser parte del horizonte analítico para, a fin de cuentas, esbozar una alternativa de abordaje de una hermenéutica del filme, a partir de la idea de una Poética del Cine.

\section{Palavras-chave}

cine, poética, método, análisis fílmico

\section{Abstract}

This article argues on the necessity and the opportunity of considerations on questions of method, concerning the procedures of film analysis. We examine the reasons why the instance of film analysis, considered as a social field, are usually so suspicious about the methodological standpoints demanded for such an analytical job. Following that point, this article defends that the methodological questions posed here are inevitable, and fruitful, and still that they would be a part of the theoretical perspectives of film analysis. These methodological observations would be of some help in drawing an analytical alternative towards a hermeneutical view of movies, departing from the idea of a poetics of film.

\section{Key words}

cinema, poetics, method, film analysis 


\section{La cuestión del método en el análisis fílmico}

T a actividad de interpretación y análisis de filmes, aunque decisiva en el ámbito de la investigación contemporánea, aparece como un oficio que puede ser realizado por muchos, de muchos modos y a través de los más variados medios. En general, se considera análisis fílmico cualquier texto que hable de películas y de sus contenidos, no importando propiamente su foco, alcance, profundidad y rigor, en un arco que incluye desde el mero comentario, pasando por la llamada crítica de cine de tipo periodístico e incluyendo, por último, el estudio académico en toda su variedad.

Tanto en una forma como en la otra no se consigue, en general, identificar una disciplina metódica que conduzca el trabajo analítico y, al mismo tiempo, sea capaz de prescribir, por lo menos, lo que debería ser, necesariamente, notado y examinado, bajo qué formas o capacidades y con cuales cuidados. Cada analista ve lo que puede o quiere y, por lo menos en principio, podría hablar de una cosa diferente de lo que hable otro analista, según el orden que le agrade y con el énfasis que desee. Frente a la ausencia de cualquier disciplina hermenéutica capaz de ofrecer garantías demostrativas suficientes para producir alguna convicción, más allá del límite de lo subjetivo y de lo íntimo, y de cualquier disciplina capaz, además, de ofrecer un terreno público y leal para la disputa interpretativa, el análisis acaba por apoyarse completamente en las cualidades peculiares del analista, o sea, en su talento, su cultura, su habilidad literaria, su suerte - o en la falta de todos ellos. Parece razonable afirmar, en este momento, que si no hay alguna disposición metódica, asentada en un consenso ampliamente compartido, es porque 
el ambiente intelectual y profesional del análisis fílmico - compuesto por periodistas, académicos y cinéfilos - no parece reconocerle sentido y necesidad.

La crítica periodística asume el lugar de orientadora de la toma de decisiones para esta especie de consumo cultural que es la apreciación de películas en el cine, en un sistema industrial que produce y circula en profusión. Se aleja cada vez más de las funciones que el ambiente cultural le atribuía en el pasado, de forma que, entre el examen analítico de los filmes, de un lado, y el registro periodístico del producto y la caracterización veloz de los elementos que permiten que un público de masa forme su decisión de consumo, por el otro, la referida crítica tiende decisivamente a quedarse con el segundo. $\mathrm{Al}$ analista le importa identificar las características fundamentales que establecen las pequeñas diferencias entre los productos en oferta, el modo que reviste talantes de orientar la decisión sobre el filme que deberá ser consumido en el próximo sábado a la noche, antes de ir al restaurante. La película en cartelera - como el plato en el menú - no precisa ser examinada, solamente caracterizada, o sea, reconocida, calificada, clasificada. El suceso en ese ambiente profesional proviene mucho menos de la calidad intrínseca del análisis ofrecido bajo la rúbrica "crítica de cine" de los periódicos contemporáneos, y mucho más de la capacidad, demostrada por el crítico, de conducir los hábitos de consumo cultural, de influenciar la decisión, de producir identificaciones entre las preferencias de consumo y las preferencias del gran público, de ver su agenda cultural asumida por la audiencia.

En los ambientes académicos, el movimiento es diverso, aunque la posición sobre el análisis pueda terminar en algo muy semejante, en lo que respecta a la disciplina metódica. Tomando como objeto algo que, si no es una práctica artística, como pretenden algunos, por lo menos es una actividad de creación, como lo admiten todos, el análisis académico de filmes gana aura artística y aires literarios y ensayísticos. En este ambiente, el reconocimiento y el suceso se dan por otros caminos, inclusive, por la calidad interna del análisis. No obstante, no parece existir, en general, una mayor buena voluntad con la idea de método de análisis. En el interior 
del campo analítico se alcanza prestigio sobre todo a través de la capacidad, demostrada por el analista, de dar cuenta de las competencias específicas de tres ambientes asociados al campo del cine: el ambiente de la realización técnica y artística, el ambiente de la apreciación, compuesto por cinéfilos y aficionados, y el ambiente de la teoría cinematográfica. Del ambiente de la realización, el analista precisa obtener el capital cognitivo constituido por la comprensión de las técnicas involucradas en la producción del objeto-filme y de los procedimientos empleados en la circulación y promoción de la mercancía-filme, además del dominio de la terminología aplicada en ambos casos. Del ambiente de la apreciación, el analista precisa demostrar que posee el capital cultural que consiste en el conocimiento de la historia del cine y de los aspectos relacionados con ella. También precisará demostrar posesión del recurso específico del ambiente académico, el dominio de la teoría cinematográfica.

El malestar con la posibilidad de exigencias metodológicas no parece, en principio, incompatible con las estrategias de distinción y con la economía del reconocimiento en el campo del análisis cinematográfico. En verdad, la disposición para atender demandas metodológicas puede variar mucho en las diversas tradiciones culturales, dependiendo del grado de autonomía de la instancia universitaria en la gestión del reconocimiento y de la distinción. Hay, de cualquier manera, una constante tensión entre las dimensiones involucradas, y la forma como esa tensión se decide en el ambiente universitario, decide también cual es el valor atribuido a la disciplina metódica en el campo del análisis fílmico. Ciertos ambientes universitarios norteamericanos y franceses, por ejemplo, presentan una mayor autonomía frente a las instancias de la realización, que la que puede observarse en los ámbitos académicos brasileños. De esa autonomía, resulta que valores de la cultura académica y científica, como el ideal de la corrección metódica o la capacidad de estar al día con el estado del arte, son reconocidos como principios importantes de distinción internos al campo. Cuando, por otro lado, en una determinada tradición cultural, el reconocimiento que se procura proviene más bien de la intimidad demostrada por el analista con 
el campo artístico y técnico del cine, son los valores artísticos los que se vuelven preponderantes. Se demanda, entonces, a la pieza analítica, que asuma las propiedades de su objeto, mientras que cualidades especialmente apreciadas en la cultura científica son consideradas indeseables $\mathrm{o}$, al menos, irrelevantes para la valoración del texto analítico. Así, el campo pasa a valorizar particularmente la habilidad literaria, la competencia expresiva, la invención retórica, la belleza del lenguaje, mucho más que la disciplina metódica, la profundidad argumentativa, la capacidad de explotar con consistencia fuentes de calidad, la objetividad y la comprobación de las posiciones presentadas. El artículo es la forma expresiva de una cultura analítica donde predomina el reconocimiento académico, mientras que el ensayo es la forma preponderante en una cultura analítica donde hasta la Academia solicita que la distinción le sea ofrecida por los ambientes de la realización y del consumo artístico.

Por otro lado, si el reconocimiento del campo social en el interior del cual se da la actividad del análisis fílmico - particularmente en lo que se refiere al modo como los agentes envueltos en tal actividad producen y generan criterios de distinción - es fundamental para el correcto entendimiento del lugar y del alcance de las cuestiones de método en los procedimientos analíticos actualmente practicados, tenemos que admitir, también, que al permanecer en este horizonte no traspasaremos el ámbito de una sociología de la cultura que, como sabemos, se esfuerza por decir cómo las cosas son, prescindiendo de la cuestión de cómo ellas deberían ser. Resta todavía la posibilidad de que nos preguntemos si, de veras, las cosas deben y precisan ser como son.

En este cambio de perspectiva, queda en evidencia el hecho de que no hay disciplina analítica que pueda evitar confrontarse con cuestiones académicas relacionadas a cualquier actividad de interpretación, cuestiones tales como la posibilidad de alcanzarse una interpretación verdadera, el control intersubjetivo de las aseveraciones analíticas, los procedimientos de análisis... Lo que significa que, de una forma o de otra, el fenómeno de la comprensión de filme el problema de su correcta interpretación son cuestiones 
que los ambientes de análisis fílmico pueden silenciar, pero no pueden, coherentemente, evitar.

Podemos afirmar, yendo directo al punto, que por detrás de todo oficio de interpretación de filmes hay un innegable problema hermenéutico, donde toman sentido las cuestiones sobre la posibilidad de un análisis correcto, de una interpretación adecuada o de una comprensión precisa de los filmes. A pesar de que frecuentemente la respuesta dada a tales cuestiones no haya estado dotada de un carácter teórico riguroso, ellas persisten desde el origen del cine, estando normalmente vinculadas al comportamiento práctico del cineasta, del apreciador de filmes o del crítico de cine, como principios para su orientación y justificativa para la evaluación exigida por su práctica.

Sería un engaño, sin embargo, convertir inmediatamente la cuestión de la comprensión e interpretación del filme - el problema hermenéutico aplicado al cine - en un problema de metodología científica del análisis fílmico. Aunque insista en que cuestiones de método para comprender filmes están autorizadas y son deseables, tales cuestiones no pueden consistir en problemas de construcción de un conocimiento cierto que pueda satisfacer el ideal metodológico de la ciencia en términos de verificabilidad de los datos del descubrimiento, de reconductibilidad de la proposición en la cual se expresa el conocimiento verdadero, a la base empírica que la autoriza y legitima, o de replicabilidad del experimento o del raciocinio del cual resultó la proposición verdadera sobre el objeto. La metodología científica tiene por objetivo asegurar que la práctica metódica de la investigación sea capaz de producir conocimiento sobre las leyes generales de funcionamiento de los fenómenos que son su objeto. En este horizonte, el suceso del procedimiento de investigación depende de su capacidad de aislar la uniformidad y la regularidad en el objeto, de forma que posibilite la previsión de cualquier sucesión de fenómenos y procesos. No obstante, tal criterio de validez no podría sernos más extraño. Comprender bien un filme difícilmente puede coincidir con la identificación de una ley general de la naturaleza del filme, a la luz de la cual la pieza particular sería nada más que el acontecimiento específico de un caso universal. Por 
menos que sepamos sobre el fenómeno de la comprensión de objetos tales como filmes, no es difícil admitir que el entendimiento de un filme resulta de la comprensión de aquello que tiene de singular, único y específico; resulta, entonces, de la comprensión de aquello que no interesa a la ciencia, en este sentido.

Pero también es igualmente inaceptable creer que el fenómeno de la comprensión de filmes no implique conocimiento y verdad y, por lo tanto, alguna especie de control intersubjetivo sobre lo que se argumenta, la posibilidad de disputa interpretativa en una porfía dotada de un grado razonablemente consistente de objetividad, las obligaciones de demostración y prueba. Es propio de la naturaleza de todo acto de comprensión, que en él alcancemos ideas, nociones, principios, conocimientos que siempre pueden ser verdaderos o falsos, adecuados o inadecuados para dar cuenta del objeto de la interpretación. Naturalmente, como problema hermenéutico auténtico, resta la pregunta sobre la naturaleza del conocimiento y de la verdad que se presenta en el acto de comprensión del filme y sobre la fuente específica de su justificación teórica y de su legitimidad especulativa.

Por lo tanto, hay un horizonte de discusión propiamente hermenéutico, en el que se sitúan con legitimidad los problemas sobre la naturaleza de la verdad que puede emerger en el entendimiento de un filme o sobre las condiciones de posibilidad de esta específica forma de comprensión que resulta del análisis e interpretación del cine. Pero hay también, en su interior, un justificado plataforma de discusión donde se presentan indagaciones sobre la naturaleza de los procedimientos y de los itinerarios analíticos, de la prueba y de la argumentación involucradas en el análisis fílmico, indagaciones, en fin, que pueden ser correctamente convocadas como cuestiones de método.

En este punto, entonces, se presentan varias alternativas en el ámbito de la discusión, para ser examinadas, probadas, eventualmente aceptadas o refutadas. La perspectiva que se presenta a seguir busca, por lo tanto, plantearse como una alternativa a ser examinada en el contexto de la discusión sobre procedimientos de análisis fílmico. No se trata de una teoría general de la interpretación del 
filme o de una respuesta global a la pregunta sobre cómo analizar un filme, sino de una perspectiva analítica que, creo, sea capaz de orientar nuestra visión y el discurso sobre la obra cinematográfica, apoyada, a su vez, en una teoría sobre el funcionamiento del filme.

\section{La poética del cine como perspectiva de análisis fílmico}

Llamaré de Poética la perspectiva analítica que aquí se pretende sistematizar o formular. No digo aquí inaugurar por que considero que sería inadecuado, por dos motivos. Ante todo, por que creo encontrar el momento fundador de tal perspectiva en el pequeño tratado de Aristóteles sobre ficción y representación teatral y literaria, conocido como Poética. Además, porque por todos lados, en la historia de las prácticas de interpretación de los filmes, fueron empleados aspectos, dimensiones e intuiciones inherentes a esta perspectiva, a pesar de que el sistema como un todo no fuese convocado, a pesar de que no se haya hecho referencia al registro histórico $\mathrm{y}$ a pesar de que tales elementos hayan aparecido mezclados a otros, en procedimientos incoherentes y asistemáticos.

La poética del filme no puede consistir en algo así como aplicar al cine lo que Aristóteles dice en su tratado sobre la literatura oral y sobre ficción escénica. No sólo porque tenemos apenas una parte del tratado, habiéndose perdido el segundo libro de la Poética tal vez en la Antigüedad, sino porque allí hay mucho de inadecuado e inaplicable, como seria lógico en una obra que lidia con referencias artísticas de, por lo menos, 24 siglos atrás. Llamaré de Poética a nuestra sistematización porque ella se apoya en algunas grandes intuiciones o descubrimientos cuyo origen es, ciertamente, el tratado homónimo del filósofo griego del siglo IV a.C.

La primera contribución retirada de la Poética de Aristóteles es preliminar y se refiere a ciertas restricciones acerca del objeto sobre el cual se reflexiona. El tratado antiguo versaba sobre la composición de representaciones en forma de historia, aquello que hoy llamaríamos de construcción de historias. Interesa rescatar lo 
que hoy llamamos de narrativas o, en lenguaje clásico, representaciones de personas que practican alguna acción. No se trata de un tratado sobre la creación artística en general. Por lo tanto, la restricción de la atención a la representación (mímesis) no implica, como erróneamente se supone, un juicio sobre el realismo como única forma artística aceptable. Restringir un objeto significa apenas delimitar el campo de interés del discurso que se está haciendo, que en ese caso es la representación ${ }^{1}$ de la acción, sobretodo en el teatro y en la literatura oral.

La primera intuición realmente importante de la Poética de Aristóteles consiste en la idea de que la obra debe ser pensada en función de su destinación. Los criterios a tener en cuenta en el cumplimiento de la destinación - finalidad de cada especie de representación - son un problema central en la Poética antigua. La destinación o dynamis de una especie de representación es lo que ella debe ser o realizar por su propia naturaleza. Más interesante es, sin embargo, que para Aristóteles la destinación de una composición cualquiera, su realización, es su efecto. Pero un efecto que no se realiza sino en función de quien disfruta o aprecia la representación. Cuando se efectúa, cuando produce un efectó, es por que una operación se transforma en obra, resultado. Y efecto es siempre efecto sobre el apreciador, para quien, justamente, ella opera, ella es obra. Así, decir que cada género de representación tiene una propia destinación equivale a decir que cada uno de ellos está destinado a provocar un determinado efecto sobre sus apreciadores. Efectos anímicos, dirá Aristóteles, efectos emocionales como el horror y la compasión, en el caso de la Tragedia.

En esta comprensión estaba implicada una idea importante sobre la naturaleza de las representaciones, que no encontraría una forma de exposición completa antes del siglo XX: Aristóteles cree que en cada uno de los géneros de representación el creador debe

1. Como el término "representación" es hoy dotado de enorme ambigüedad, es mejor que se aclare que la mímesis aristotélica es un tipo de composición que implica el reconocimiento y la semejanza. Reconocimiento como "representación de" alguna cosa, como "semejante a" algo; "algo" y "alguna cosa" de nuestra experiencia. 
buscar el efecto apropiado y debe buscarlo prioritariamente sobre cualquier otro tipo de efecto posible. Eso significa que a cada género corresponde un efecto propio y conveniente. Pero significa también que el papel del creador, del compositor de representaciones (el poeta, para Aristóteles), es proyectar, prever y organizar estratégicamente aquellos efectos que se realizarán en la apreciación, que son adecuados para su género de obra. El apreciador, por lo tanto, debe ser previsto en la producción y su ánimo debe ser conducido en el acto creador de la composición que posteriormente apreciará. El efecto es semilla plantada en la creación, que brotará solamente en la apreciación.

De forma que, si la composición es obra únicamente cuando se realiza, como efectividad, como efecto, en la apreciación, por otro lado es obra que se realiza por arte, o sea, a través de las destrezas del poeta, a quien cabe prever y conducir la apreciación. Lo que significa que la creación es actividad de argucia, planeamiento, previsión y provisión de efectos. El creador tendrá que construir, de algún modo, la recepción de su obra, tendrá que anticipar y prever los efectos que desencadenará. Creación es estrategia, estrategia de producción de efecto, estrategias de concierto y de organización de los elementos de la composición dirigidos a la previsión y a la solicitación de determinados resultados (específicos de cada género). Dicho de otro modo: los efectos que se realizan en la apreciación, son previstos en la creación (póiesis), en la poesía de la obra.

En el seno de tales descubrimientos, gana forma un programa de estudios que se ocupará, entonces, con los efectos de la composición y de la relación entre tales efectos realizados y las estrategias presentes en tal composición. A ese programa de estudios lo llamo aquí propiamente de Poética.

Una poética aplicada al cine tendrá que constituirse como un programa teórico y metodológico que asume como propios los presupuestos de las dos tesis que hereda de la poética clásica. El primer presupuesto es una tesis sobre la naturaleza de la pieza cinematográfica: el filme puede ser entendido correctamente si es visto como un conjunto de dispositivos y estrategias destinadas a la producción de efectos sobre su espectador. Tales dispositivos y 
estrategias pueden ser identificados, aislados y relacionados con la familia de efectos procurados por el realizador. La perspectiva metodológica que se deriva de esto indica un procedimiento analítico cuya destinación consistiría en señalar los recursos y medios estratégicamente puestos en el filme. La poética estaría, entonces, orientada para la identificación y tematización de los artificios que, en la película, solicitan ésta u otra reacción, éste o aquel efecto en el ánimo del espectador. En ese sentido, estaría capacitada a ayudar a entender por qué y cómo puede llevarse al apreciador a reaccionar de ésta o de aquella manera frente a un filme.

El segundo presupuesto es una tesis sobre la naturaleza de la apreciación del filme: una película no existe como obra en ningún lugar o momento, a no ser en el acto de su apreciación por cualquier espectador. Como una sinfonía no existe como música ni en la partitura ni en el CD, sino en el acto de su apreciación cuando es ejecutada, un filme sólo existe en el momento de la experiencia fílmica, sólo existe en el momento en que emerge en sentidos y efectos. De ello se deriva una perspectiva metodológica que exige, del intérprete de filmes, que su atención se desvíe de la comprensión del realizador aislado y de sus propuestas y se concentre en el filme cuando es experimentado; en la pieza cinematográfica, cuando apreciada; en el texto, cuando leído. La primera perspectiva metodológica se completa con la idea de que nos interesan los recursos y medios estratégicamente puestos en el filme a medida en que, justamente a partir de ellos, el apreciador de la obra ejecuta sus efectos.

No sería incorrecto hacer derivar del presupuesto aristotélico una prescripción metodológica de tipo fenomenológico: debemos atenernos a la cosa misma. A la cosa que está en la experiencia. Debemos atenernos al filme que se aprecia, dejando en el plano secundario el filme imaginado o deseado por el realizador o el filme que debería corresponder a sus proyectos. La instancia de la realización es secundaria frente a lo que interesa centralmente: la instancia de la obra, entendida como una pieza que se realiza cuando es experimentada, apreciada.

Etienne Souriau y Gilbert Cohen-Séat, en su filmología, mencionan el nivel filmofónico de la pieza cinematográfica o del 
filme funcionando como objeto percibido por espectadores durante el tempo de su proyección ${ }^{2}$. La experiencia fílmica que interesa a la poética no es exactamente el momento empírico de la apreciación del filme, que interesa principalmente, a nuestro entender, a una etnografía de la audiencia. Nos interesa la apreciación como instancia que se realiza empíricamente a través de uno o de múltiples actos circunstanciales de disfrute de la obra y, sobretodo, como instancia que está prevista en el texto de la obra. La experiencia fílmica es la experiencia de la apreciación del filme, o del filme como objeto apreciado por cualquier espectador, real o posible.

Las perspectivas metodológicas que se derivan de los presupuestos de la poética se encajan recíprocamente en el acto analítico. Al abordar el filme como obra, o sea, como composición de dispositivos y estrategias orientadas a ejercer efectos sobre la apreciación, cabe al analista, ante todo, identificar el lugar de la apreciación, como instancia donde el filme opera, donde produce sus efectos, donde se presenta por primera vez como filme. El lugar de la apreciación no es nada más que el sistema de los efectos operados. Identificarlo equivale a aislar las sensaciones, los sentimientos y los sentidos que se realizan en el apreciador durante su experiencia y por causa de ella.

Dicho de otra forma: en el programa teórico y metodológico de la poética, el principio de todo es la identificación de aquello que compone la experiencia fílmica, de aquello que la película hace con sus espectadores, de aquello que emerge de la cooperación entre intérprete y texto. Como veremos enseguida, esta experiencia se estructura como una composición, variable en su materialidad singular, de sensaciones, sentimientos y sentidos. Alcanzar tal extracto de la experiencia significa la identificación de los tipos y modos de sensaciones, sentimientos y sentidos que un filme determinado es capaz de producir en la apreciación.

El procedimiento metodológico solicita que se vaya de la experiencia fílmica al propio filme como composición. Con eso, remontamos del efecto a la estrategia, de la apreciación al texto donde

2. Apud Aumont et al. A estética do filme. Campinas: Papirus, 1995: p. 202. 
la apreciación es programada. Remontarse del efecto a su programación en la pieza fílmica es realizar un recorrido inverso al de la producción de la obra. Así, por ejemplo, de emociones como horror, conmoción, angustia, suspenso o extrañeza se remontará a las estrategias y dispositivos que son capaces de generarlos, se estudiará el mecanismo sobre la base del cual funcionan, se procurará establecer leyes generales de la programación de efectos en filmes, se intentará identificar los códigos internos de funcionamiento de la composición del filme a partir de los géneros de efectos en que se especializan.

Esta base fundamental del procedimiento metodológico supone una comprensión de la pieza fílmica como algo que se compone de tres dimensiones (debiendo ser metódicamente descompuestas en el análisis): efectos, estrategias y medios o recursos. Medios son recursos o materiales que son ordenados y dispuestos en vista a la producción de efectos en la apreciación. Estrategias son tales medios estructurados, compuestos y agenciados como dispositivos, de forma de programar efectos propios de la obra. Los efectos son la efectuación de medios y estrategias sobre la apreciación, son la pieza cinematográfica como resultado, como obra.

Los materiales de que se compone una obra fílmica son muy variados y pueden ser clasificados de muchas maneras. Podemos intentar agruparlos por los parámetros ya tradicionales en el arte cinematográfico y podremos distribuir los materiales en visuales, sonoros, escénicos y narrativos. El parámetro visual, que ha concentrado la mayor parte de la reflexión sobre los materiales del cine, incluye desde los aspectos específicamente plásticos, como las dimensiones cromáticas y compositivas del filme (línea de foco, distribución de los elementos, posición del objeto) hasta los aspectos genéricamente fotográficos, tales como incidencia angular, encuadre, código de escalas de planos, nitidez de la imagen, contraste, tonalidad, brillo, foco (selección y profundidad de campo, fuente de luz), pasando por los aspectos fotográficos de naturaleza específicamente cinematográfica, como movimientos de cámara y raccords, y por los efectos visuales. El parámetro sonoro implica todos los aspectos acústicos, desde la música al sonido, mientras 
que el parámetro escénico incluye desde la dirección y actuación de los actores, hasta los escenarios y figurines. Por fin, en el caso de filmes narrativos, los parámetros narrativos que el cine divide con la literatura, el teatro, la ópera, las historietas, etc. y que se refieren a la composición de la historia, su argumento y trama, sus peripecias y sus desenlaces. Obviamente, estos últimos parámetros son tan importantes para el cine narrativo contemporáneo como los parámetros visuales, justificando por enésima vez la comprensión del cine como arte compuesta, mixta. Notemos que todos esos aspectos no son exclusivamente cinematográficos y que, por lo tanto, una teoría que se ocupe solamente con lo que se presume exclusivo del cine no sería suficiente para explicar un filme desde el punto de vista de sus materiales.

Los materiales de la composición cinematográfica se transforman en medios para la producción del filme cuando son empleados o estructurados con vistas a la producción de efectos. Desde el punto de vista del texto fílmico tenemos un primer extracto de empleo de tales materiales en aquello que consideramos un uso técnico del recurso cinematográfico. Esta es, ciertamente, la base de todo, desde el punto de vista de la realización y es, ciertamente, la base material técnica de la existencia de algo como un filme. Se trata del uso orientado por la eficacia o eficiencia técnica del recurso. Sabemos, por ejemplo, lo que es una buena fotografía de cine, una buena iluminación o un buen desempeño del acto fílmico, desde el punto de vista del dominio de las técnicas cinematográficas involucradas.

Sobre esta base puede ser establecido un segundo tipo de empleo del recurso cinematográfico, orientado por propósitos expresivos, frecuentemente tomados como artísticos. En este caso, el uso de los recursos sirve para configurar un modo particular de expresión, orientado por valores estéticos o por peculiaridades del lenguaje. La pieza, entonces, recibe el tono, la marca, el estilo, el lenguaje peculiar de algún agente de la instancia de la realización. Los usos técnicos y "de lenguaje" de los recursos cinematográficos no se confunden y, a veces, entran en conflicto. Muchas veces, por ejemplo, se compromete la eficiencia técnica de una fotografía en 
nombre de propuestas expresivas de carácter estético o simplemente estilístico o, viceversa, las audacias estéticas en el uso de los recursos son evitadas en nombre de la primacía de la eficacia técnica.

Básicamente, un filme se compone de recursos cinematográficos empleados con habilidad técnica y, eventualmente, con una marca de estilo y lenguaje proveniente del realizador. Todo eso, sin embargo, es una materialidad a ser debidamente formada por complicados mecanismos de producción de efectos en la apreciación. Por eso mismo, cambiamos de nivel cuando nos referimos a los usos expresivos de los recursos cinematográficos, donde vemos los recursos dominados por la competencia técnica y artística, controlados por una hábil máquina de programación de efectos.

Esta máquina funciona con, por lo menos, tres modos de composición de la obra, correspondientes a los tres tipos de efecto convocados en el apreciador: sensación, sentido y sentimiento.

En primer lugar, tenemos una programación de efectos que podemos propiamente llamar, aunque imperfectamente, de composición estética (de aisthesis, sensación), en el sentido de que aquí los medios y los materiales son estructurados para producir efectos sensoriales. Así como el artista plástico puede producir una instalación con pajillas transparentes para producir un efecto o sensación de rugosidad en quien la aprecia (prescindiendo del hecho de, si además de hacer sentir alguna cosa, la instalación quiera también decir algo), también los elementos que componen la pieza fílmica (el color, la luz, un ritmo de montaje, una banda sonora etc.) pueden ser dispuestos para producir una determinada sensación en el espectador del filme. Sensación que el analista precisa identificar para, entonces, aislar la estrategia empleada.

En segundo lugar, tenemos una estructuración que podemos llamar de composición comunicacional, pues medios y materiales son organizados para producir sentido, o sea, para componer mensajes, transferir ideas o hacer pensar determinadas cosas. El efecto deseado en ese caso es un evento conceptual: los significados o sentidos. Los medios y recursos aquí se cifran o codifican en la instancia estratégica de la realización para ser descifrados o decodificados como texto en la instancia operativa 
de la apreciación. Operación de desciframiento que se realiza tanto como posesión de los códigos cotidianos como acudiendo a códigos aptos para la revelación de sentidos figurados. Si en el primer tipo de composición, la obra produce una sensación específica, en el segundo modo, la obra dice alguna cosa 0 , por lo menos, hace pensar en algo.

Ninguno de esos dos modos de composición estaba previsto en la Poética clásica, mas el tercer modo encuentra allí, ciertamente, su origen. Se trata de la composición que podemos llamar, para homenajear los orígenes, de composición poética. En ella, los elementos son dispuestos, los recursos, medios y materiales son agenciados para producir efectos emocionales o anímicos en el espectador. En esa composición, los materiales no se estructuran para producir una sensación sino un sentimiento; no se organizan para hacer emerger una idea o una noción, sino para generar un estado de espíritu, un estado de ánimo.

El primer tipo de composición programa la experiencia sensorial de la apreciación. El segundo tipo hace lo mismo con la experiencia conceptual, mientras que el tercero, tiene en vista específicamente la experiencia emocional generada por el filme. Nos resta todavía la pregunta - que todavía no soy capaz de responder - si estos tipos de efectos expresan la totalidad de la experiencia o si tendríamos que identificar alguna cosa más que el filme pueda hacer con el apreciador.

Los modos de estructuración del filme no operan como capas yuxtapuestas; el filme es, él mismo, una composición en la cual se sintetizan varias composiciones y usos de los elementos y materiales. El filme como un todo es la programación de efectos, la logística que dirige y coordina las estrategias fundamentales y los usos de sus recursos elementales. Además, no sería correcto imaginar que los filmes se componen, en igual medida, de las diversas composiciones elementales. Cada filme, como obra singular, es un programa artístico específico y solicita, en una específica medida y realizando un conjunto preciso de opciones, la naturaleza y los modos de sus propios efectos. Cada filme, cada clase o género, tiene un especial sabor, un color particular, 
consecuencia del modo peculiar como se combinan los elementos y de la cantidad y calidad de los ingredientes en juego. Así, añadiéndole algo a Aristóteles, el filme no se califica sólo por el género de efectos emocionales que prevé y solicita, sino también por la determinación del tipo de composición que implica y de la familia de efectos que engendra.

La historia del arte en general y la historia de la teoría del filme en particular son una continua sucesión de disputas entre escuelas sobre aquello que el arte cinematográfico y el filme son o deberían ser. $\mathrm{Y}$, frecuentemente, los términos de las opciones son justamente las tres formas de composición indicadas antes. ¿Un filme cualquiera debe o no debe contener un mensaje, una denuncia o una información? ¿Cuando eso sucede, es a costa de sus propiedades artísticas y expresivas? ¿Una buena película no debe ser comprometida, criticar determinados modos de vida, hacer pensar y defender las causas justas? ¿Aquello que vuelve un filme artístico no es justamente el hecho de que no está allí para hacer pensar en nada (¡no es una tesis, es arte!), sino para expresar, hacer sentir? ¿Un filme hecho para la conmoción no estaría degradando su función artística, por un lado, o su función crítica, por otro?

Es evidente que las escuelas artísticas, orientadas para defender lo específicamente artístico como lo no-conceptual, insistirán en que lo que caracterizaría específicamente el filme como arte estaría en su composición estética y en el empleo artístico de los recursos cinematográficos. En ese sentido, las vanguardias estéticas y sus innovaciones de lenguaje y de sus recursos expresivos son las preferidas por estas escuelas. Por su parte, las escuelas conceptuales insisten en la función comunicativa del filme, en el buen y en el mal sentido. En el buen sentido, cuando el cine ejerce su función crítica de la sociedad y de sus modos de vida, cuando denuncia, cuando hace pensar, cuando se compromete con las causas éticamente justas. En el mal sentido, porque la lectura crítica del cine demostraría cuánto la industria cinematográfica produce mensajes orientados a la manutención del status quo, a la dominación del hombre sobre el hombre y para el apoyo y adhesión al modo de vida de las sociedades centrales en la forma actual del capitalismo. Común tanto a la 
perspectiva del cine de vanguardia estética como a la perspectiva del cine comprometido es la evaluación negativa sobre la composición poética. El cine de mensajes desprecia el cine de lágrimas tanto como lo hace el cine estético.

Esas disputas, en la medida en que solicitan una opción entre los modos de composición, acaban por ser una disputa política. Todas esas formas de composición fueron parte de las formas de realización artística desde siempre y no parecen dar señales de agotamiento. Nuestra experiencia nos dice que ellas están frecuentemente combinadas en las obras de arte que apreciamos. Pero nos dice también que la fenomenología de las formas de composición es muy variable y que la opción a priori de una o de otra, no nos ayudaría a comprender mejor el hecho artístico. Hay obras en que una forma de composición es predominante y, de alguna manera, silencia o controla todas las otras: es el caso de los filmesdenuncia, de los filmes de vanguardias expresivas o de los melodramas lacrimosos, por ejemplo, en que la búsqueda de producción de ideas, sensaciones o sentimientos agotan prácticamente todos los recursos utilizados en la obra. Hay obras en que los programas de efectos se combinan de manera más homogénea, hay obras en que apenas dos de ellos están presentes. Ninguna de esas formas del fenómeno es, por ello, más o menos artística que la otra.

En ese sentido, un filme siempre debe ser capaz de indicar el modo como quiere ser apreciado, el modo y la dosis con los cuales las varias composiciones son, a su vez, compuestas en un todo que es ofrecido para la apreciación. Es la obra que gobierna, también en el cine, los parámetros de su propia apreciación y, por consiguiente, los parámetros de su propio análisis. Para Jakobson un trabajo literario se hace con un grupo de códigos en interacción, pero de modo tal que un código es, siempre, dominante. En ciertos poemas líricos, por ejemplo, aliteraciones y asonancias, que serían códigos sonoros, controlarían las inflexiones de los otros códigos como narrativa, repetición, imágenes. De modo análogo, tal vez deba decirse que las varias formas de composición interactúan constantemente en el interior de la pieza cinematográfica, pero que, en lo atinente a sus tendencias, hay por lo menos una forma que controla las otras 
composiciones y sobre ellas predomina. Así, reclamar de un melodrama que no realice denuncia social, por ejemplo, es exigir del filme que renuncie a su código dominante, a la composición poética, y a sus estrategias de conmoción, para asumir un código que, en él, ciertamente no constituye una estrategia importante.

Se estudia poquísimo, en teoría y estética del cine, la composición estética y poética de los filmes. En consecuencia, ellas son aplicadas rara y desordenadamente en el análisis e interpretación de filmes. Y hacen falta. Si, por un lado, la instancia de la realización manipula los recursos y materiales del filme para producir los efectos deseados porque ciertamente conoce y domina la composición poética como tecnología y savoir faire, por otro, la teoría y el análisis no saben qué hacer con esos materiales y los acaba desperdiciando en su abordaje teórico o en su aproximación analítica. La semiótica aplicada al cine, por ejemplo, se ha revelado eficiente como estudio interno de la mecánica de los filmes en sus estrategias de producción de sentido y significación. Su meta es perfectamente comprensible si fuese entendida como la proposición de modelos habilitados a explicar cómo un filme adquiere significado en el acto de su apreciación o interpretación. Estará fuera de su órbita específica de competencia, si pretende examinar el filme como estrategia sensorial o sentimental. Se trata, por lo tanto, de dimensiones a ser exploradas.

En el horizonte teórico y metodológico de la poética del cine, la actividad fundamental del analista es, por lo tanto, moverse entre la apreciación y el texto del filme, identificando los efectos que cada película realiza sobre el apreciador para, después, remontarse a los programas dispuestos en la composición de la obra.

\section{Bibliografía}

ANDREW, J. 1989. 1976. As principais teorias do cinema: uma introdução. Rio de Janeiro: J. Zahar.

ARISTOTELES. Poética. 1992. Trad. Eudoro de Souza. São Paulo: Ars Poetica. 
AUMONT, J. et al. 1995. 1992. Estética do filme. Campinas: Papirus.

BAUDRY, J.-L. 1978. L'effet cinéma. Paris: Albatros.

BOURDIEU, P. 1996. As regras da arte. São Paulo: Cia. das Letras.

BYWATER, T. y SOBCHACK, T. 1989. Introduction to film criticism. Major critical approaches to narrative film. New York/ London: Longman.

CARROLL, N. 1988. Mystifying Movies: fad \& fallacies in contemporary film theory. New York: Columbia University Press.

CASEBIER, A. 1976. Film Appreciation. New York: Hartcourt Brace Jovanovich.

ECO, U. (1990) I limiti dell'interpretazione. Milano: Bompiani.

1994. Seis Passeios pelos bosques da ficção. São Paulo: Companhia das Letras.

GADAMER, H.-G. 1960. Wahrheit und Methode. Grundzüge einer philosophisce Hermeneutik. Tübingen: Mohr.

GAUDREAULT, A. 1989. Du littéraire au filmique. Système du récit. Paris: Méridiens Klicksieck.

GOMES, W. 1992. Metáfora da Diferença. In: Trans/Form/Ação (Unesp), 15: 131-147.

1996. Estratégias de produção de encanto: o alcance contemporâneo da Poética de Aristóteles. In: Textos de Cultura e Comunicação, 35: 15-37.

JAKOBSON, R. 1973. Questions de poétique. Paris: Seuil.

. 1991. Lingüística e poética. In: ID. Lingüística e comunicação. São Paulo: Cultrix: 118-162.

METZ, C. 1968-1972. Essai sur la signification au cinéma. $2 \mathrm{vol}$. Paris: Klincksieck.

. 1979. Le signifiant imaginaire. Paris: UGE.

MEUNIER, J.-P. 1969. Universitaire.

PAREYSON, L. 1988. Estetica. Teoria della formatività. Milano: Bompiani.

VANOYE, F. e GOLIOT-LÉTÉ, A. 1994. 1992. Ensaio sobre a análise filmica. Campinas: Papirus. 